\title{
Systolic time intervals in the differential diagnosis of constrictive pericarditis and cardiomyopathy
}

\author{
J. C. Ghose, S. K. Mitra, and M. K. Chhetri \\ From the Department of Cardiology, Institute of Postgraduate Medical Education and Research, Calcutta, \\ India
}

Systolic time intervals (STI) were measured from simultaneously recorded phonocardiograms, carotid pulse tracings, and electrocardiograms in 11 patients with constrictive pericarditis and in 10 patients with cardiomyopathy to assess the value of STI in the differential diagnosis of the two conditions. The predicted ejection fraction was calculated from the STI. The results were compared and found significantly different in the two groups of patients. The ratio PEP/LVET and the ejection fraction were found to have greater discriminatory values and separated the two groups clearly.

Measurement of STI, a simple, noninvasive bedside technique, appears to be useful in distinguishing between constrictive pericarditis and cardiomyopathy.

Clinical differentiation between constrictive pericarditis and cardiomyopathy, particularly the constrictive or the restrictive variety, is often difficult. Even sophisticated procedures like cardiac catheterization and angiocardiography may not yield a definite diagnosis and surgical exploration is sometimes necessary. Measurement of systolic time intervals (STI) is a simple, noninvasive bedside technique for assessing the left ventricular performance.

In myocardial dysfunction such as in cardiomyopathy there is reduced myocardial contractile performance leading to a decrease in the maximal rate of rise in isovolumetric pressure which results in prolongation of the pre-ejection period (PEP) and a reduced rate of myocardial fibre shortening and thus a decrease in stroke volume and ejection fraction. In constrictive pericarditis, on the other hand, the basic problem is one of impaired filling rather than of emptying, with normal or near normal systolic contraction and ejection fraction. This basic physiological difference prompted us to study the STI in these two disorders to assess their value in differential diagnosis.

\section{Patients and methods}

Studies were made in 11 patients with chronic constrictive pericarditis, proved by cardiac catheterization and surgery in all but two patients, and in 10 patients Received 21 April 1975. with cardiomyopathy with typical clinical and haemodynamic features.

Fig. 1 shows the method of measuring the STI simultaneously from a phonocardiogram, carotid pulse tracing, and electrocardiogram recorded on a Gallileo three-channel, direct-writing recorder at a paper speed of $100 \mathrm{~mm} / \mathrm{s}$. A crystal microphone for recording the heart sounds was placed at a site over the praecordium which prior auscultation had shown to be the best for recording the aortic component of the second heart

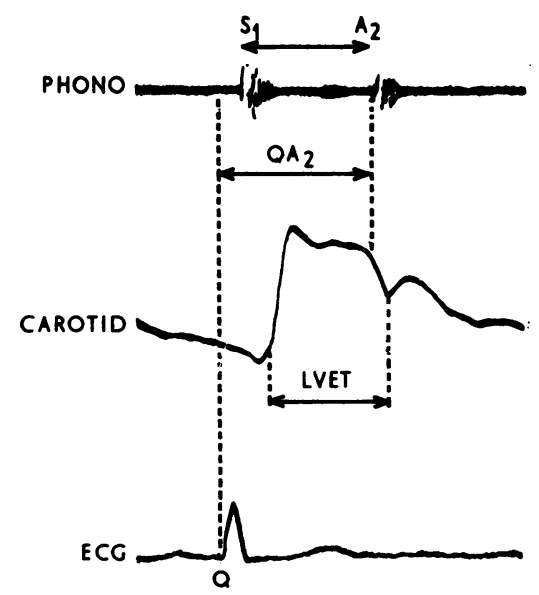

FIG. 1 Measurement of systolic time intervals from simultaneous phonocardiagram, carotid pulse tracing and electrocardiogram. 


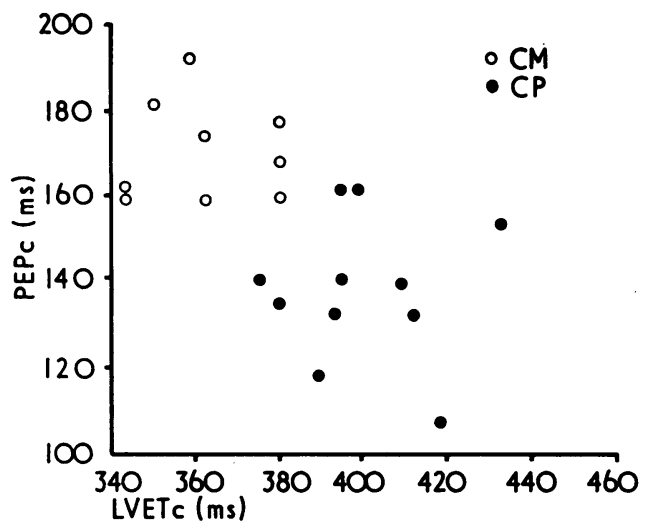

FIG. 2 Relation between pre-ejection period (PEPc) and left ventricular ejection time (LVETc) in constrictive pericarditis and cardiomyopathy.

sound. The right carotid arterial pulse was recorded with a funnel-shaped pick-up attached by a polyethylene tubing to a piezo-electric crystal microphone. The electrocardiographic lead, usually lead II, that clearly showed the $Q$ wave was selected. The time intervals were calculated as the mean value from at least 10 cardiac cycles.

Left ventricular ejection time (LVET) was measured from the onset of the carotid upstroke to the incisura of the dicrotic notch. Pre-ejection period (PEP) was measured indirectly by subtracting left ventricular ejection time from the total electromechanical systole $\left(\mathrm{Q}-\mathrm{A}_{2}\right)$ : thus $\mathrm{PEP}=\mathrm{QA}_{2}-\mathrm{LVET}$. The measurements of PEP and LVET were corrected for heart rate and sex by using the regression equation of Weissler, Harris, and Schoenfeld (1968). PEP/LVET ratio was calculated which was not significantly influenced by heart rate and sex. The predicted ejection fraction (EF) was calculated from the systolic time intervals by the regression equation of Garrard, Weissler, and Dodge (1970).

Routine right and left heart catheterization were performed in all the patients.

\section{Results}

The haemodynamic findings in the 11 cases of constrictive pericarditis are shown in Table 1 . The cardiac index was normal, with low stroke volume and stroke work, in most of the patients. The left ventricular and right ventricular end-diastolic pressures were raised and nearly equal with a diastolic plateau.

The haemodynamic findings in the 10 cases of cardiomyopathy (Table 2) show a low or low normal cardiac index, low stroke volume and stroke work,

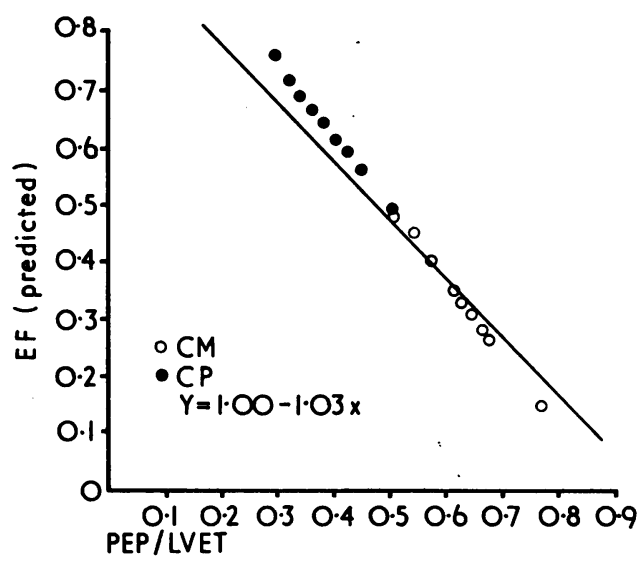

FIG. 3 Relation between PEP/LVET ratio and ejection fraction (EF) in constrictive pericarditis and cardiomyopathy.

TABLE 1 Haemodynamic findings in 11 patients with constrictive pericarditis

\begin{tabular}{|c|c|c|c|c|c|c|c|c|c|}
\hline Case No. & $\begin{array}{l}\text { Age } \\
\text { (years) }\end{array}$ & $\begin{array}{l}C I \\
\left(l / \min \text { per } m^{2}\right)\end{array}$ & $\begin{array}{l}S V \\
\text { (ml/beat) }\end{array}$ & $\begin{array}{l}\text { LVEDP } \\
(m m \mathrm{Hg})\end{array}$ & $\begin{array}{l}P C W P \\
(m m \mathrm{Hg})\end{array}$ & $\begin{array}{l}M P A P \\
(m m \mathbf{H g})\end{array}$ & $\begin{array}{l}R V E D P \\
(m m \mathrm{Hg})\end{array}$ & $\begin{array}{l}M R A P \\
(m m H g)\end{array}$ & $\underset{(g-m)}{L V S W}$ \\
\hline 1 & 18 & $2 \cdot 6$ & 27 & 33 & 30 & 35 & 33 & 28 & $18 \cdot 3$ \\
\hline 2 & 17 & 3.0 & 34 & 25 & 24 & 27 & 25 & 17 & 24.0 \\
\hline 3 & 12 & $3 \cdot 2$ & 21 & 25 & 22 & 28 & 22 & 20 & $27 \cdot 1$ \\
\hline 4 & 12 & 3.8 & 30 & 25 & 19 & 19 & 19 & 15 & $21 \cdot 2$ \\
\hline 5 & 26 & $2 \cdot 0$ & 23 & 35 & 22 & 31 & 20 & 22 & 14.0 \\
\hline 6 & 59 & 3.0 & 68 & 20 & 18 & 33 & 20 & 14 & 61.9 \\
\hline 7 & 25 & $4 \cdot 5$ & 59 & 22 & 25 & 22 & 20 & 19 & $53 \cdot 7$ \\
\hline 8 & 17 & 3.0 & 53 & 27 & 21 & 30 & 27 & 16 & $46 \cdot 8$ \\
\hline 9 & 30 & 4.6 & 60 & 28 & 28 & 36 & 28 & 21 & 46.5 \\
\hline 10 & 15 & 3.7 & 35 & 25 & 24 & 31 & 25 & 21 & 29.9 \\
\hline 11 & 35 & $2 \cdot 1$ & 28 & - & 25 & 30 & 30 & 25 & - \\
\hline
\end{tabular}

$\mathrm{CI}=$ cardiac index; $\mathrm{SV}=$ stroke volume; $\mathrm{LVEDP}=$ left ventricular end-diastolic pressure; $\mathbf{P C W P}=$ pulmonary capillary wedge pressure; $\mathbf{M P A P}=$ mean pulmonary artery pressure; RVEDP =right ventricular end-diastolic pressure; $M R A P=$ mean right atrial pressure; LVSW = left ventricular stroke work.

Conversion from Traditional Units to SI Units: $1 \mathrm{~mm} \mathrm{Hg} \approx 0.133 \mathrm{kPa}$. 
TABLE 2 Haemodynamic findings in 10 patients with cardiomyopathy

\begin{tabular}{|c|c|c|c|c|c|c|c|c|c|}
\hline Case No. & $\begin{array}{l}\text { Age } \\
\text { (years) }\end{array}$ & $\begin{array}{l}C I \\
\left(l / \min \text { per } m^{2}\right)\end{array}$ & $\begin{array}{l}S V \\
\text { (ml/beat) }\end{array}$ & $\begin{array}{l}\text { LVEDP } \\
(m m \mathrm{Hg})\end{array}$ & $\begin{array}{l}P C W P \\
(m m \mathrm{Hg})\end{array}$ & $\begin{array}{l}M P A P \\
(m m \mathrm{Hg})\end{array}$ & $\begin{array}{l}\text { RVEDP } \\
(m m \mathrm{Hg})\end{array}$ & $\begin{array}{l}M R A P \\
(m m \mathrm{Hg})\end{array}$ & $\underset{(g-m)}{L V S W}$ \\
\hline 1 & 35 & 2.4 & 42 & 5 & 7 & 16 & 2 & 7 & $42 \cdot 2$ \\
\hline 2 & 32 & 1.5 & 30 & 15 & 15 & 29 & 12 & 7 & 29.0 \\
\hline 3 & 16 & $2 \cdot 3$ & 45 & 10 & 10 & 14 & 8 & 6 & $42 \cdot 3$ \\
\hline 4 & 11 & 3.0 & 30 & 15 & 12 & 30 & 17 & 8 & $29 \cdot 3$ \\
\hline 5 & 30 & 1.5 & 20 & 35 & 25 & 34 & 20 & 12 & 13.6 \\
\hline 6 & 15 & $1 \cdot 7$ & 24 & 25 & 25 & 24 & 23 & 18 & $21 \cdot 2$ \\
\hline 7 & 30 & $2 \cdot 2$ & 40 & 28 & 30 & 34 & 25 & 27 & $46 \cdot 7$ \\
\hline 8 & 23 & 1.8 & 24 & 30 & 18 & 36 & 18 & 13 & $17 \cdot 6$ \\
\hline 9 & 30 & 3.3 & 50 & 12 & 10 & 19 & 2 & 2 & $51 \cdot 0$ \\
\hline 10 & 30 & $3 \cdot 4$ & 64 & 15 & 16 & 30 & 5 & 3 & $47 \cdot 8$ \\
\hline
\end{tabular}

Conversion from Traditional Units to SI Units: $1 \mathrm{~mm} \mathrm{Hg} \approx 0.133 \mathrm{kPa}$.

and a raised or normal left ventricular end-diastolic pressure.

The relation between the corrected PEP (PEPc) and corrected LVET (LVETC) in the two groups of patients is shown in Fig. 2. The PEPc in patients with cardiomyopathy was greater than $160 \mathrm{~m} / \mathrm{s}$ and the LVETc less than $380 \mathrm{~m} / \mathrm{s}$, while the PEPc in patients with constrictive pericarditis was less than $160 \mathrm{~m} / \mathrm{s}$ and the LVETc greater than $380 \mathrm{~m} / \mathrm{s}$. There was only a slight overlap between the two groups. The relation between the PEP/ LVET ratio and the predicted EF is shown in Fig. 3. Again there is a clear discrimination between the two groups of patients. The PEP/LVET ratio of 0.5 and the $\mathrm{EF}$ of 0.5 are the dividing lines.

Statistical analysis of the haemodynamic findings (Figs. 4, 5, 6, and 7) shows highly significant differences between the two groups of patients.

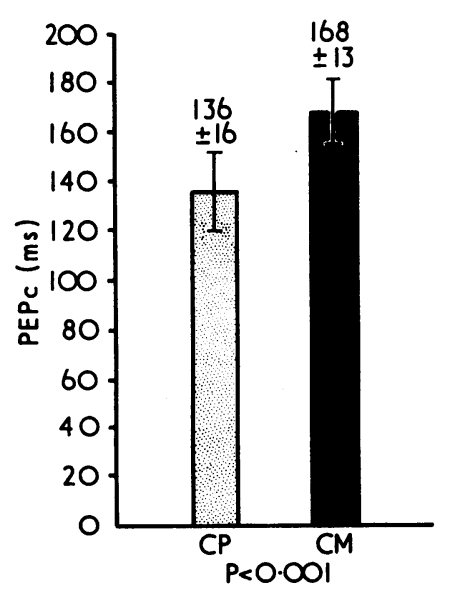

FIG. 4 Statistical analysis of results of PEPc in constrictive pericarditis and cardiomyopathy.

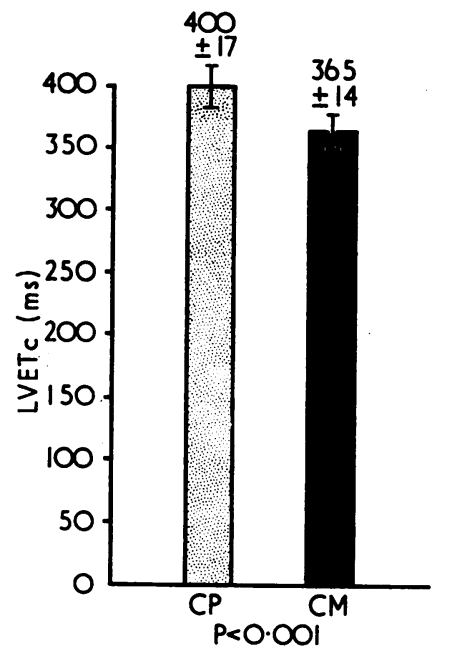

FIG. 5 Statistical analysis of the results of LVETC in constrictive pericarditis and cardiomyopathy.

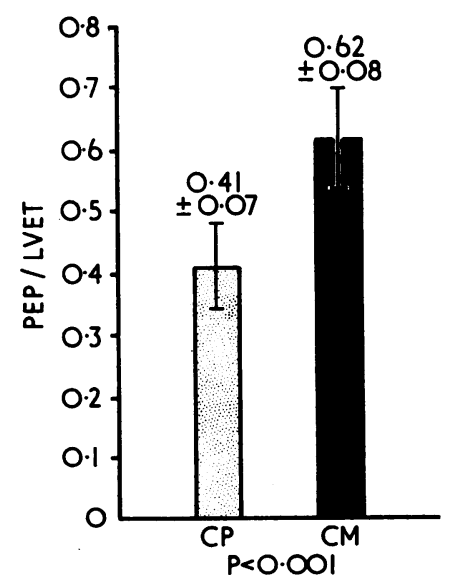

FIG. 6 Statistical analysis of the results of PEP/ LVET ratio in constrictive pericarditis and cardiomyopathy. 


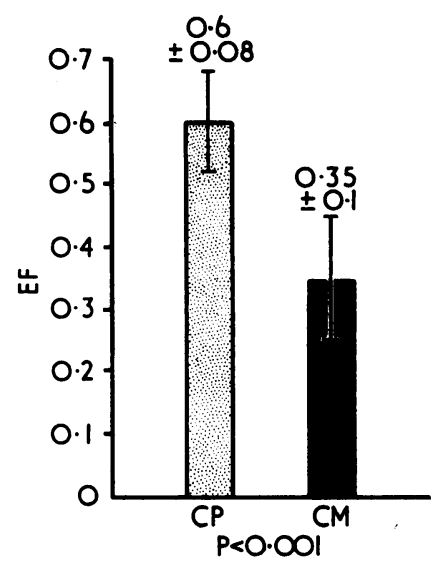

FIG. 7 Statistical analysis of the results of EF in constrictive pericarditis and cardiomyopathy.

\section{Discussion}

The systolic time intervals are a most effective and sensitive method of evaluating left ventricular performance. Alterations in the intervals-the increase in PEP and the decrease in LVETclosely correlate with other haemodynamic measurements of left ventricular dysfunction such as reduced cardiac output and stroke volume, decreased ejection fraction, and depressed left ventricular contractile performance as measured by peak left ventricular $\mathrm{dP} / \mathrm{dt}$ (Weissler et al., 1968, 1969; Garrard et al., 1970; Ahmed et al., 1972). In left ventricular dysfunction there is a decrease in the maximal rate of rise in isovolumetric pressure (Gleason and Braunwald, 1962) resulting in an increase in the time needed for the intraventricular pressure to reach the aortic diastolic pressure leading to prolongation of the pre-ejection period. When PEP is prolonged but the total electromechanical systole remains unchanged the left ventricular ejection time must decrease.

In cardiomyopathy there is gross myocardial dysfunction with decrease in myocardial contractility, as shown by left ventricular cineangiography and a low cardiac output and ejection fraction (Fowler, Gueron, and Rowlands, 1961; Yu et al., 1964; Croxson and Raphael, 1969; Hamby et al., 1970; Ghosh, Neelakantan, and Chhetri, 1974). The situation is, however, different in constrictive pericarditis, where the clinical picture of congestive heart failure is due to impaired ventricular filling with normal or near normal myocardial function (Armstrong, Lewis, and Gotsman, 1973; Gaasch, Peterson, and Shabetai, 1974). Thus the STI serve to differentiate between the two conditions (Armstrong et al., 1973).
The STI clearly discriminated between the two groups of patients in our study. Significant abnormalities in STI were found in the cases of cardiomyopathy even when the patients were not in failure. PEP, LVET, PEP/LVET, and predicted EF differed between the two groups in nearly all cases, the most noticeable difference being in the PEP/LVET ratio and the EF. We therefore believe that systolic time intervals measured by simple, noninvasive bedside methods can differentiate between constrictive pericarditis and cardiomyopathy even when invasive procedures like cardiac catheterization and angiocardiography may fail.

We are grateful to the Surgeon Superintendent, S.S.K.M. Hospital, and the Director, Institute of Postgraduate Medical Education and Research, Calcutta, for their help and co-operation.

\section{References}

Ahmed, S. S., Levinson, G. E., Schwartz, C. J., and Ettinger, P. O. (1972). Systolic time intervals as measures of the contractile state of the left ventricular myocardium in man. Circulation, 46, 559.

Armstrong, T. G., Lewis, B. S., and Gotsman, M. S. (1973). Systolic time intervals in constrictive pericarditis and severe primary myocardial disease. American Heart fournal, 85, 6.

Croxson, R. S., and Raphael, M. J. (1969). Angiographic assessment of congestive cardiomyopathy. British Heart fournal, 31, 390.

Fowler, N. O., Gueron, M., and Rowlands, D. T., Jr. (1961). Primary myocardial disease. Circulation, 23, 498.

Gaasch, W. H., Peterson, K. L., and Shabetai, R. (1974). Left ventricular function in chronic constrictive pericarditis. American fournal of Cardiology, 34, 107.

Garrard, C. L., Jr., Weissler, A. M., and Dodge, H. T. (1970). The relationship of alterations in systolic time intervals to ejection fraction in patients with cardiac disease. Circulation, 42, 455.

Ghosh, J. C., Neelakantan, C., and Chhetri, M. K. (1974). Peripartal cardiomyopathy-A clinical and haemodynamic study. Indian Heart fournal, 26, 213.

Gleason, W. L., and Braunwald, E. (1962). Studies on the first derivative of the ventricular pressure pulse in man. fournal of Clinical Investigation, 41, 80.

Hamby, R. I., Catangay, P., Apiado, O., and Khan, A. H. (1970). Primary myocardial disease. Clinical, hemodynamic and angiographic correlates in fifty patients. American fournal of Cardiology, 25, 625.

Yu, P. N., Cohen, J., Schreiner, B. F., Jr., and Murphy, G. W. (1964). Hemodynamic alterations in primary myocardial disease. Progress in Cardiovascular Diseases, 7, 125.

Weissler, A. M., Harris, W. S., and Schoenfeld, C. D. (1968). Systolic time intervals in heart failure in man. Circulation, 37, 149.

Weissler, A. M., Harris, W. S., and Schoenfeld, C. D. (1969). Bedside technics for the evaluation of ventricular function in man. American fournal of Cardiology, 23, 577.

Requests for reprints to Dr. J. C. Ghose, 245 Lower Circular Road, Calcutta 700020, India. 